\title{
Linear Lichen Planopilaris of the Face: Case Report and Review
}

\author{
Daniel Asz-Sigalla Ana Cecilia González-de-Cossio-Hernández ${ }^{b}$

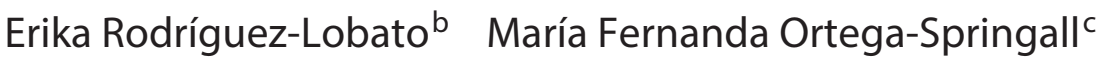 \\ María Elisa Vega-Memije ${ }^{c}$ Roberto Arenas Guzmán ${ }^{d}$

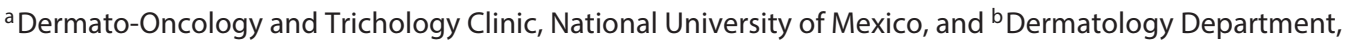 \\ 'Investigation Department, and dMycology Section, 'Dr. Manuel Gea González' General Hospital, \\ México City, Mexico
}

\section{Established Facts}

- Linear lichen planopilaris of the face is a rare variant of lichen planopilaris.

\section{Novel Insights}

- Only a few cases of linear lichen planopilaris of the face have been reported in the literature.

- In contrast to lichen planus and lichen planopilaris, linear lichen planopilaris of the face is more common in middle-aged men.

\section{Key Words}

Lichen planopilaris of the face · Linear lichen planopilaris ·

Face

\section{Abstract}

We describe the case of a 45-year-old man who presented with a 5-month history of unilateral pruritic linear erythematous papules and atrophy on the chin and mandibular area. Dermoscopy showed areas of cicatricial alopecia with absence of follicular openings, perifollicular erythema and pigment. Lichen planopilaris of the face is a rare variant with only 13 cases reported in the literature.

(c) 2016 S. Karger AG, Base

\section{Introduction}

Linear lichen planopilaris of the face is a rare variant of lichen planopilaris (LPP) and only few cases have been reported in the literature. The etiology is unknown and is characterized by pigmented follicular papules that progress to atrophy in a linear distribution. Histological findings are similar to those found in LPP, but this rare variant predominantly affects middle-aged men. 
Fig. 1. a Irregular linear erythematous, pigmented and atrophic lesion on the chin and mandibular area. b Three-month clinical follow-up after treatment.
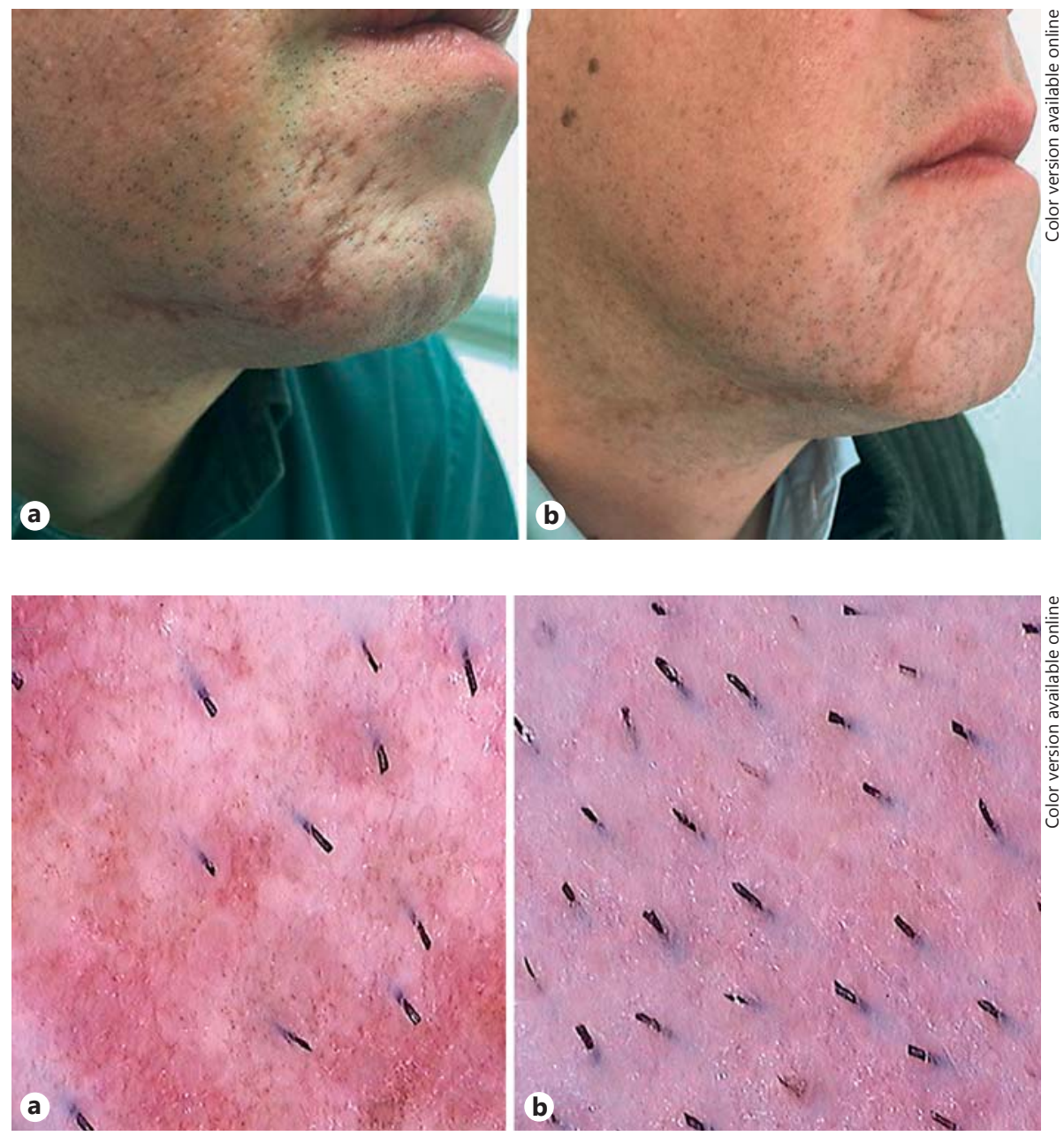

Fig. 2. a Areas of cicatricial alopecia with absence of follicular openings, perifollicular erythema and pigment. b Comparative picture of the contralateral healthy side (dermoscopy, $\times 40$ ).

\section{Discussion}

LPP or lichen planus follicularis, a subtype of lichen planus, is an inflammatory condition characterized by patchy or diffuse hair loss with erythematous papules and keratotic follicular lesions that evolve to cicatricial alopecia $[1,2]$. Although rare, it represents $25 \%$ of the cases of cicatricial alopecia [3] and is more frequent in women (70-80\%), with a peak age of onset between 30 and 60 years $[1,4]$. The etiology of this condition is poorly understood. It has been proposed that it is caused by an autoimmune reaction against follicular antigens mediated by T-lymphocytes $[1,4,5]$.

Traditionally, it can be divided into three different clinical types: classic type, frontal fibrosing alopecia, and Graham-Little-Piccard-Lassueur syndrome [2, 3]. Other variants reported in the literature include scarring alopecia of the vulva [6], lichen planus follicularis tumidus [7], and linear LPP of the face. 
Fig. 3. a Presence of folliculocentric lichenoid infiltrate at the infundibulum sparing the lower portion (hematoxylin and eosin stain, original magnification $\times 20$ ). b Closeup showing perifollicular lymphocytic infiltrate, vacuolization of basal cells and pigment incontinence (hematoxylin and eosin stain, original magnification $\times 40)$.

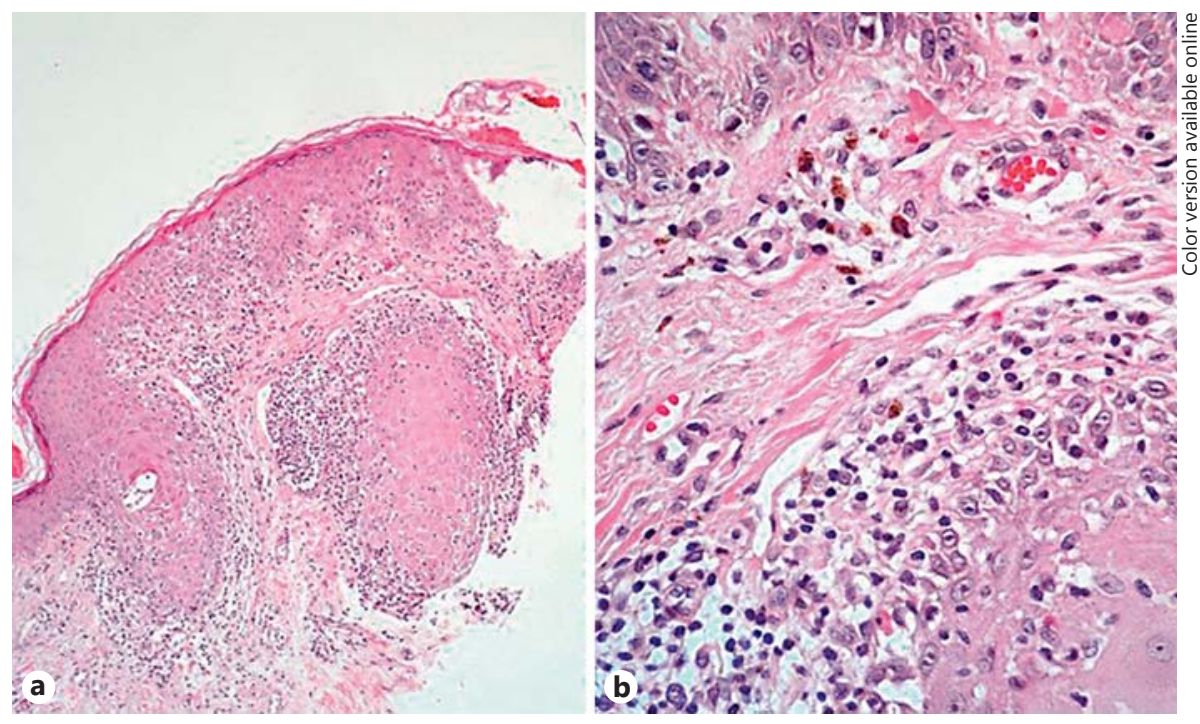

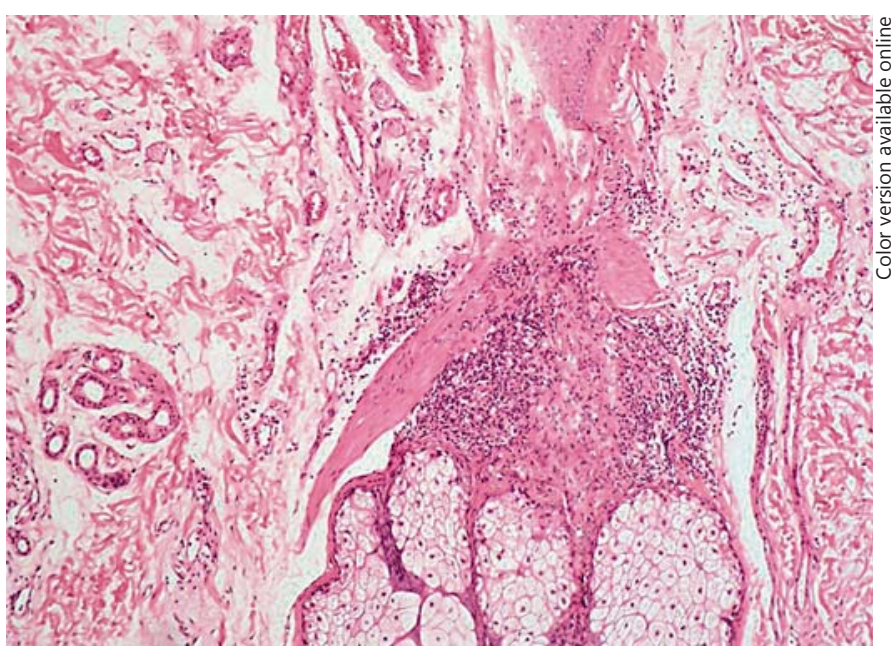

Fig. 4. Lymphocytic infiltrate that predominates in the infundibulum and does not involve the sebaceous glands (hematoxylin and eosin stain, original magnification $\times 20$ ).

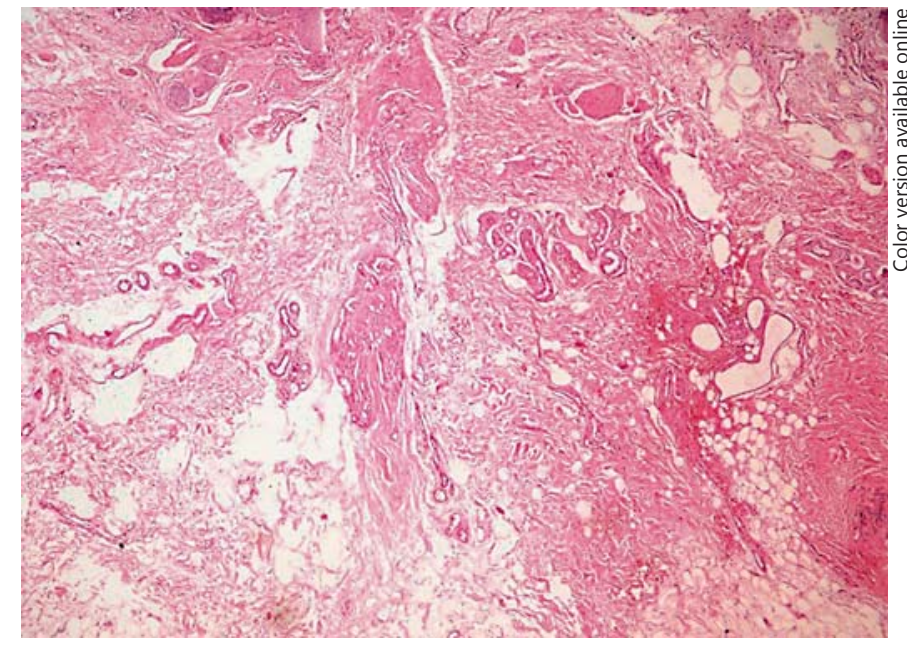

Fig. 5. Fibrosis and atrophic hair follicles are seen (hematoxylin and eosin stain, original magnification $\times 10$ ).

Table 1. Reported cases of LPP of the face

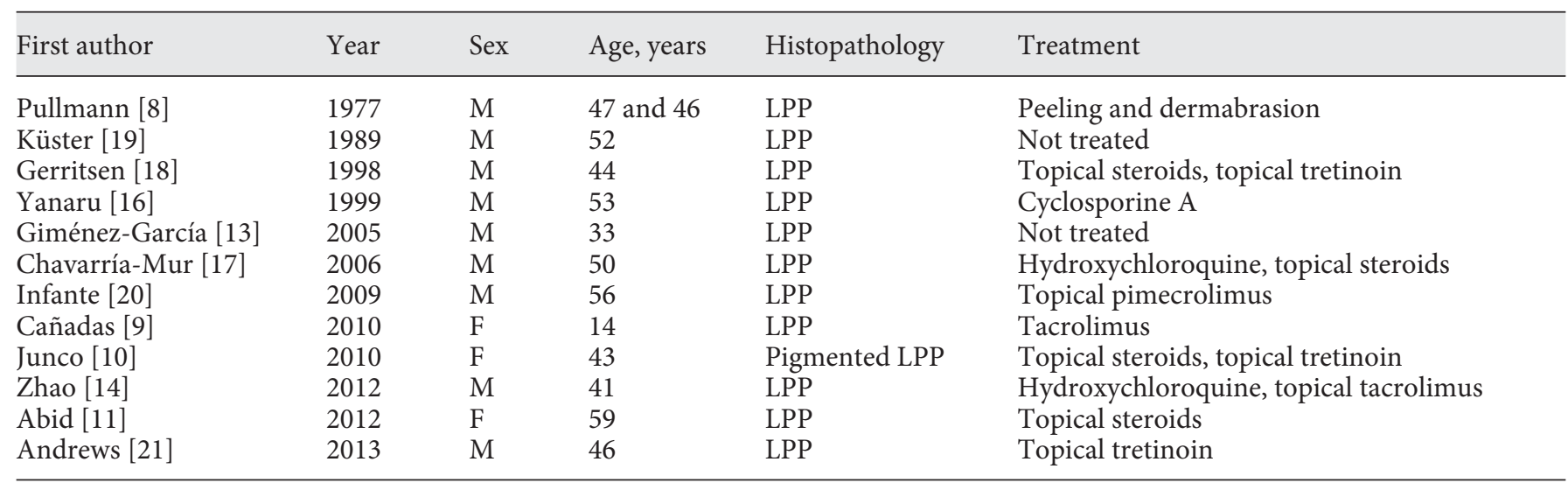


Linear LPP of the face is a rare variant of LPP first described by Pullmann and Gartmann in 1977 [8], and to our knowledge, this is the 14th case reported in the literature (table 1). In contrast to LPP, linear LPP of the face is more common in men between 33 and 56 years, with only three female patients described in the literature [9-11].

Physical examination reveals pigmented red-brown papules, perifollicular erythema, scaling and secondary atrophy in a linear distribution $[8,9]$. Although usually asymptomatic, it can be associated with itching or pain. LPP of the face appears most commonly on the cheeks, mandibular area and chin. Only two cases on the trunk have been documented $[2,12]$. It has been proposed that it may appear following the lines of Blashko and in areas of koebnerization $[13,14]$.

The clinical differential diagnosis includes red linear lichen planus, linear atrophoderma of Moulin and linear morphea. Red linear lichen planus never resolves leaving skin atrophy, linear atrophoderma of Moulin is more common in children and predominates on the trunk and extremities, and linear morphea presents with skin sclerosis $[13,14]$.

Histological findings are the same as the ones found in LPP with folliculocentric lichenoid infiltrate at the level of the infundibulum sparing the lower portion, destruction of the basement membrane with vacuolization of the basal layer and damage of the outer epithelial sheets of the follicles $[14,15]$. Hypergranulosis, acantosis, hyperkeratosis, Civatte bodies, pigment incontinence, and follicular plugging can be seen. There are only a few reports of the immunofluorescence in this entity and the results are not consistent. Immunofluorescence is important to differentiate LPP from lupus erythematosus.

There is no generally accepted treatment regimen for linear LPP of the face. Successful regimens reported include oral cyclosporine [16], topical tacrolimus and pimecrolimus [9], hydroxychloroquine or topical steroids $[14,17]$. Little success was reported with tretinoin cream [18]. The lesions of the patients reported by Küster et al. [19] and Giménez-García et al. [13] improved spontaneously without therapy.

Prognosis of disease is uncertain and permanent atrophy has an esthetic impact on the patients. We propose the use of laser and fillers to improve the cosmetic results.

\section{Statement of Ethics}

The patient's consent was obtained. The authors have no ethical conflicts to declare.

\section{Disclosure Statement}

The authors have no conflicts of interest to disclose.

\section{References}

1 Chieregato C, Zini A, Barba A, Magnanini M, Rosina P: Lichen planopilaris: report of 30 cases and review of the literature. Int J Dermatol 2003;42:342-345.

2 Gupta SN, Palceski D: Lichen planopilaris presenting as truncal alopecia: a case presentation and review of the literature. Cutis 2003;72:6366.

3 Meinhard J, Stroux A, Lünnemann L, Vogt A, Blume-Peytavi U: Lichen planopilaris: epidemiology and prevalence of subtypes - a retrospective analysis in 104 patients. J Dtsch Dermatol Ges 2014;12:229-235.

4 Lyakhovitsky A, Amichai B, Sizopoulou C, Barzilai A: A case series of 46 patients with lichen planopilaris: demographics, clinical evaluation, and treatment experience. J Dermato$\log$ Treat 2015;26:275-279.

5 Harries MJ, Paus R: The pathogenesis of primary cicatricial alopecias. Am J Pathol 2010; 177:2152-2162.

6 Grunwald MH, Zvulunov A, Halevy S: Lichen planopilaris of the vulva. Br J Dermatol 1997; 136:477-478.
7 Jaworsky C, Gilliam A: Immunopathology of the human hair follicle. Dermatol Clin 1999; 17:561-568.

8 Pullmann H, Gartmann H: Unusual garlandlike lichen planopilaris of the face (in German). Hautarzt 1977;28:206-207.

9 Cañadas NG, Luna PC, Etcheverry MD, Nocito MJ, Posse ML, Marchesi C, et al: Linear lichen planopilaris of the face. Dermatol Online J 2010;16:11.

10 Junco M, Escalaya G, Vicuña C, Sandoval B, Espinoza H, Romero M: Linear lichen planus pilaris pigmentosus of the face in a woman (in Spanish). Folia Dermatol Peru 2010;21:40-44.

11 Abid M: A rare case of facial linear lichen planopilaris with a response to topical corticosteroids (Poster reference number 5477). J Am Acad Derm 2012;AB40.

12 Baker K, Pehr K: Linear lichen planopilaris of the trunk: first report of a case. J Cutan Med Surg 2006;10:136-138.

13 Giménez-García R, Lázaro-Cantalejo TE, Sánchez-Ramón S, Velasco-Fernandez C: Linear lichen planopilaris of the face. J Eur Acad Dermatol Veneorol 2005;19:770-772.
14 Zhao N, Qu T: Linear lichen planopilaris of the face. Eur J Dermatol 2012;22:691-692.

15 Farah RS, Ferguson NN, Swick BL: Lichen planopilaris. Cutis 2013;92:17-18.

16 Yanaru E, Ueda M, Ichihashi M: Linear lichen planopilaris of the face treated with low-dose cyclosporine A. Acta Derm Venerol 1999;80:212.

17 Chavarría-Mur E, Fernández-Vilariño E, Lázaro-Tremul C, Aizpún-Ponzán M, del Cura E: Liquen plano folicular lineal de la cara. Med Cutan Iber Lat Am 2006;36:300-302.

18 Gerritsen MJP, de Jong EMGJ, van de Kerkof PCM: Linear lichen planopilaris of the face. J Am Acad Dermatol 1998;38:633-635.

19 Küster W, Kind P, Hölzle E, Plewig G: Linear lichen planopilaris of the face. J Am Acad Dermatol 1989;21:131-132.

20 Infante L, Martinez Del Sel J, Donatti L, Allevato $\mathrm{M}$, Cabrera $\mathrm{H}$ : Liquen plano folicular lineal de la cara. Act Terap Dermatol 2009;32: 14-17.

21 Andrews I, Williams R: Facial lichen planopilaris: an atypical presentation and review of a new variant. J Am Acad Dermatol 2013; P6318:AB105. 